\title{
THE NEED FOR IMPROVED MANAGEMENT OF THE SUBSURFACE
}

\author{
HOLGER KESSLER ${ }^{1}$, RICKY L. TERRINGTON ${ }^{1}$, HANS-GEORG SOBISCH ${ }^{2}$, JAN \\ GUNNINK $^{3}$, RÜDIGER LUDWIG ${ }^{4}$, EGON HARMS $^{5}$, KEITH TURNER ${ }^{6}$, ROGER MOORE $^{7}$ \\ ${ }^{1}$ British Geological Survey, Keyworth, Nottingham, United Kingdom NG12 5GG \\ e-mail hke@bgs.ac.uk \\ ${ }^{2}$ INSIGHT GmbH, Cologne, Germany \\ ${ }^{3}$ TNO, Utrecht, Netherlands \\ ${ }^{4}$ BGR, Hannover, Germany \\ ${ }^{5}$ OOWV, Oldenburg, Germany \\ ${ }^{6}$ Colorado School of Mines, Colorado, USA \\ ${ }^{7} \mathrm{CEH}$, Wallingford, United Kingdom
}

\begin{abstract}
SUMMARY
The subsurface is used intensively to support economic stability and growth. Human interaction with the shallow subsurface ranges from exploitation of resources, accommodation of utilities, harnessing of energy (ground source heat pumps) and storage of waste. Current practice of managing these shallow subsurface zones is far from ideal. Many subsurface interventions are preceded by feasibility studies, predictive models or investigative measures to mitigate risks or predict the impacts of the work. However, the complex interactions between the anthropogenic structures and natural processes mean that a holistic impact assessment is often not achievable. By integrating these subsurface infrastructures within three dimensional framework models, a comprehensive assessment of the potential hazards in these shallow subsurface environments may be made. Some Geological Survey Organizations (GSOs) are currently developing subsurface management systems that will aid decision making in the shallow subsurface [1]. The British Geological Survey (BGS) is developing an open Environmental Modeling Platform [2] to provide the data standards and applications to link models, numerical simulations and ultimately socio-economic models so as to generate predictive responses to questions concerning sustainable us of the subsurface.
\end{abstract}

\section{INTRODUCTION}

GSOs increasingly employ advances in technology to better visualize and understand natural environmental systems [1, 2]. Instead of two-dimensional paper maps and reports, many GSOs now produce three-dimensional geological framework models and groundwater flow models as their standard and systematic output [3, 4]. However, these models only assess specific aspects of the Earth's system, such as the flow of groundwater to an abstraction borehole, or the availability of water for irrigation [5]. Although the outputs are often impressive in terms of accuracy and visualization, they are inherently limited in their ability to simulate the response to feedbacks from other models of the Earth system, in particular the impact of human actions. Additionally, three-dimensional models of the natural environment have often not been used to plan or design components of the civil infrastructure, particularly those located in the shallow subsurface environment [6]. The shallow subsurface environment is a vital human resource we use for transport (road and train tunnels), utilities and telecommunications links, exploitation of resources and storage of waste and by-products. The complex interactions between the anthropogenic structures and natural processes mean that a holistic impact assessment is often not achievable using past methods. The shallow subsurface is an increasingly critical part of the socio-economic system, and complex use suggests that a more coordinated approach to its regulation and management is required [7, 8]. The design and management of buried utilities has become an especially economically important aspect in many urban environments. In Europe, the UK Water Industry Research (UKWIR) organization has led many recent UK and European initiatives to improve the way in which buried utilities are designed and managed, while the European Street Works Advisory Council (ESWRAC) involves utilities across Europe and has successfully lobbied for European Commission research on asset location and condition assessment. These two organizations have supported two on-going research programs (funded by the UK's Engineering and Physical Sciences Research Council) that rely on accurate 
geological models of the shallow subsurface - the Mapping the Underworld project [7] and the VISTA project [9]. The BGS has already undertaken collaborations with members of both these research teams to identify appropriate methods for mapping the locations of existing buried utilities [10]. The importance of accurate subsurface information is clearly demonstrated when unanticipated conditions lead to failures during construction of new underground works. For example, the collapse of the building containing all of Cologne's archives on March 3, 2009 occurred as the new Cologne subway was being constructed along the street in front of the building [11] (Figure 1). This has resulted in the loss of large amounts of Cologne's historical records extending back over a millennium and among the most extensive in Europe. Thus the loss to society is considerable.

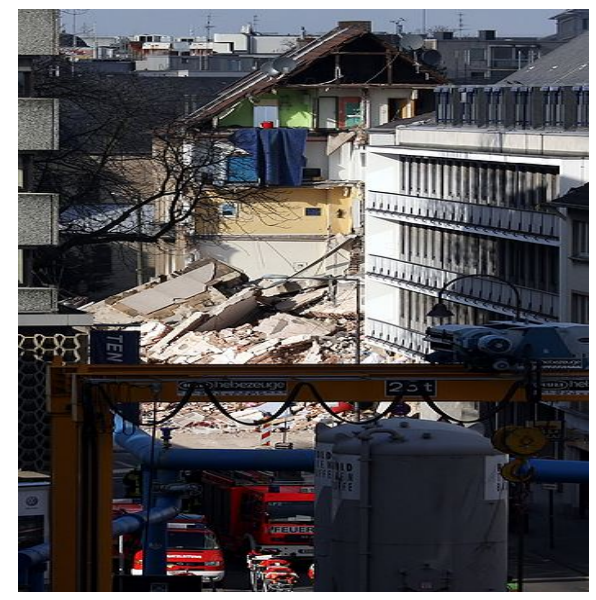

Figure 1. Collapse of the Cologne archives building in March, 2009. [11]

\section{THE VISION OF AN INTEGRATED SUBSURFACE INFORMATION SYSTEM}

The BGS and some other GSOs are starting to develop methodologies and applications to tackle the wide ranging issues that concern the management of the subsurface [12, 13]. These new methodologies will be able to replicate the spatial and temporal decision-making currently achieved by using GIS systems, but overcome the limitations of the two-dimensional nature of GIS technologies. The Environmental Modeling Platform (EMP) is an initiative [2] that aims to build a community to provide the data standards and applications to seamlessly link numerical models, nonnumerical models (e.g. geological models) and concepts together (Figure 2). Furthermore, the EMP will provide the platform to include socio-economic factors such as population growth, urban growth and the price of commodities.

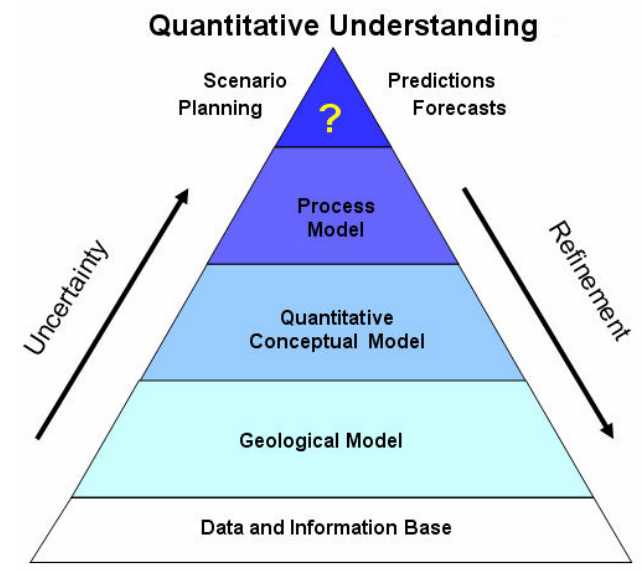

Figure 2. Schematic diagram showing the relationships between models and data (modified from [5])

A significant problem affecting the development of the EMP is the incompatible nature of models from different disciplines [14]. This could be in terms of data format, scientific concepts or First International Conference on Frontiers in Shallow Subsurface Technology

20-22 January, 2010, Delft, The Netherlands 
programming language. The BGS has contributed some way to trying to integrate the geological and hydroscience data and models using common languages and software standards to overcome these barriers. Two examples of initiatives that are beginning to change the way we interact between science disciplines are OpenMI (Open Model Integration Environment), and GeoSciML (Geoscience Mark-up Language). OpenMI provides a standard that allows models to exchange data with each other on a time step by time step basis as they run. It thus facilitates the modeling of process interactions. The models may come from different developers, represent processes from different domains, be based on different concepts, and have different spatial and temporal resolutions [15]. GeoSciML aims to deliver a common conceptual data model on the nature and structure of the geoscience information, to which data held in individual databases can be mapped and consequently transferred between users [16]. Using common practices and languages like those described above will facilitate the development of a subsurface information system which will aim to inform planners, regulators and other decision makers through three- and four-dimensional models of the combined surface and subsurface environment. Dissemination of subsurface data and models will be via commonly used tools such as TNO's DINOLoket Web service [1] and software like the Subsurface Viewer which allows the integration of artificial subsurface and surface infrastructure with natural environment features such as geological structures (Figure 3). The means of disseminating data and information just described is only the beginning of meeting the needs of planners, regulators and other decision makers by visualizing data in the context of the real world. There is an identifiable need for a comprehensive multi-dimensional subsurface management system forming the basis for spatial, volumetric, temporal decision making in the same way as today's GIS systems are used for two dimensional spatial planning, insurance risk assessment, or emergency planning. It is vital that this system is not developed in isolation from the real end-users and also that the system is able to deal with the wide variety of subsurface models that exist in the GSOs across the world.

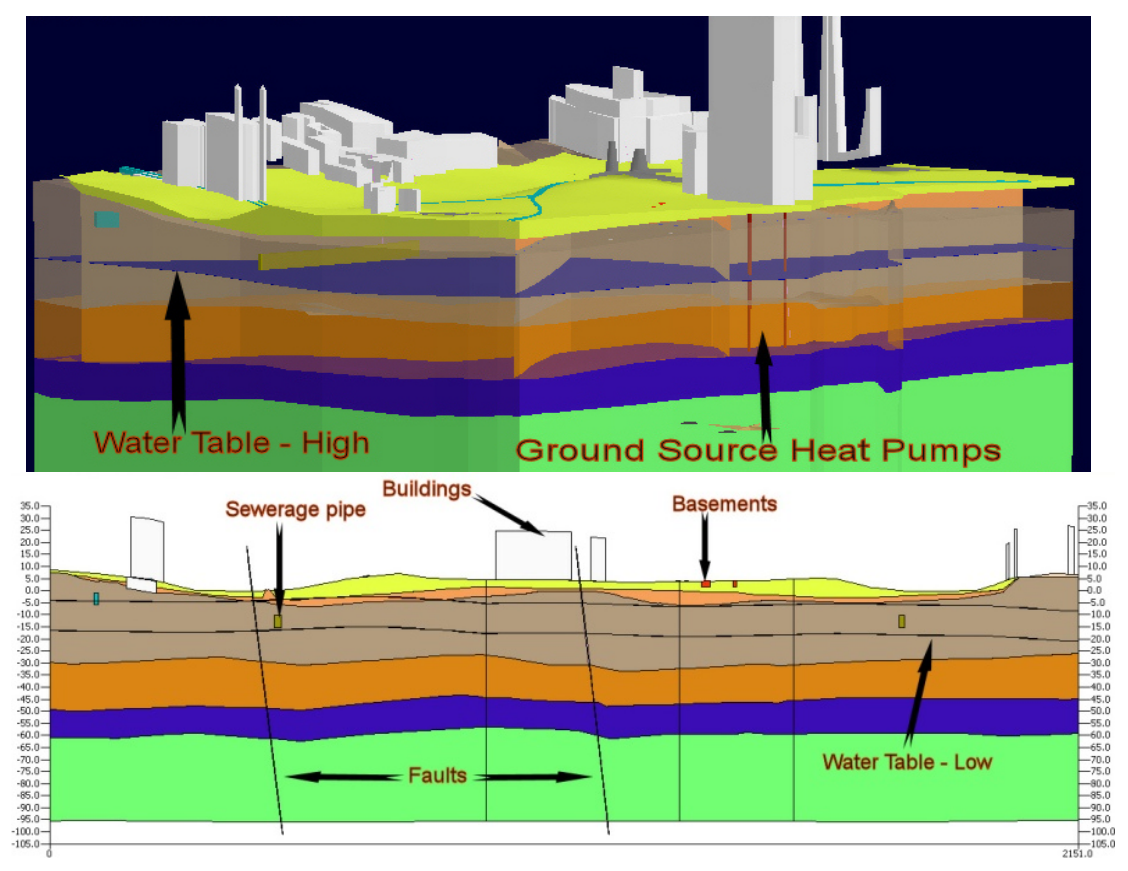

Figure 3. A mock-up model with artificial infrastructure integrated within the geological model visualised in 3D and in cross-section using the Subsurface Viewer [13].

\section{CONCLUSIONS}

Attributed geological and groundwater models are means to an end, not an end in themselves. They are more parts of a jigsaw of data and models needed by decision makers to respond to the pressing human and environmental questions in today's changing world. GSOs, as the custodians of strategic earth science knowledge and information, have to rise to the challenge and leave their traditional comfort zone to interact with the wider science and user community to link up their data and 
knowledge with others and provide the outcomes in a form that can be used readily by decision makers [17] Development of integrated systems that facilitate the management of the combined subsurface and surface and not just elements of these zones will be a primary focus of GSOs such as the TNO, BGR and the BGS leading to open and interoperable methodologies and applications to enable more effective economic development and sustainable use of the subsurface environment.

\section{REFERENCES}

[1] TNO 2009. DINOLoket Website. http://www.dinoloket.nl/

[2] DAEM Project - Concept note. 2009. http://daem.wikidot.com/concept-note

[3] Kessler, H., Mathers, S., Lelliot, M., Hughes, A., and MacDonald, D., 2007. Rigorous 3D geological models as the basis for ground water modeling, Three-Dimensional geologic mapping for groundwater applications, Workshop extended abstracts, Denver, Colorado.

[4] Hughes et al., 2008. Zoom into GSI3D. In: Mathers, S. J. (Ed.)., 2008. Extended Abstracts of the $2^{\text {nd }}$ International GSI3D Conference, British Geological Survey, Keyworth, United Kingdom 2-3 September 2008.

[5] Sharpe, D. R., Hinton, M. J., Russell, H. A. J., and Desbarats, A. J., 2002. The need for basin analysis in regional hydrogeological studies, Oak Ridges Moraine, Southern Ontario. Geosciences Canada, 29, 1, pp. 3-20.

[6] Kessler, H., Turner, A.K., Culshaw, M.G. \& K.R. Royse. 2008. Unlocking the Potential of Digital 3D Geological Subsurface Models for Geotechnical Engineers, Proceedings, II European Conference of International Association for Engineering Geology, Madrid, 15-19 September, 2008, 8p.

[7] Metje, N. et al. 2007. Mapping the Underworld - State-of-the-Art Review, Tunnelling and Underground Space Technology, Vol. 22, pp.568-586.

[8] McMahon W., Burtwell M.H. and Evans M. 2005. Minimising Street Works Disruption: The Real Costs of Street Works to the Utility Industry and Society, UK Water Industry Research, London.

[9] VISTA Project Website: http://www.vistadtiproject.org

[10] Rogers, C.D.F. et al. 2009. Predictive Mapping of Soil Geophysical Properties for GPR Utility Location Surveys, Proceedings of the 5th International Workshop on Advanced Ground Penetrating Radar, Granada, Spain, May 27-29, p. 60-67.

[11] http://en.wikipedia.org/wiki/Historical_Archive_of_the_City_of_Cologne. Image courtesy of Raimond Spekking. Under License cc-by-sa-3.0, http://creativecommons.org/licenses/by-sa/3.0/

[12] Self, S. and Entwisle, D. 2006. The structure and operation of the BGS National Geotechnical Properties Database, Internal Report IR/06/092, British Geological Survey.

[13] Kessler, H., Mathers, S.J. and Sobisch, H-G. 2009. The capture and dissemination of integrated 3D geospatial knowledge at the British Geological Survey using GSI3D software and methodology, Computers \& Geosciences, Vol.35, No.6, pp.1311-1321.

[14] Turner, A.K. 2006. Challenges and Trends for Geological Modelling and Visualisation, Bulletin of Engineering Geology and the Environment, Vol. 65, No. 2, pp. 109-127.

[15] OpenMI 2009. OpenMI Website: http://www.openmi.org

[16] Sen, M. and Duffy, T. 2005. GeoSciML: Development of a generic GeoScience Markup Language, Computers \& Geosciences, Vol. 31, No. 9, pp. 1095-1103.

[17] Rosenbaum, M.S. and Turner, A.K., [Editors] 2003. New Paradigms in Subsurface Prediction, Lecture Notes in the Earth Sciences, Number 99, Springer-Verlag, Berlin, 397p. 